\title{
Retrievals of heavy ozone with MIPAS
}

\author{
Bastiaan Jonkheid ${ }^{1}$, Thomas Röckmann ${ }^{1}$, Norbert Glatthor ${ }^{2}$, Christof Janssen ${ }^{3}$, Gabriele Stiller ${ }^{2}$, and \\ Thomas von Clarmann ${ }^{2}$ \\ ${ }^{1}$ Institute for Marine and Atmospheric Research, Utrecht University, Utrecht, the Netherlands \\ ${ }^{2}$ Karlsruher Institut für Technologie, Institut für Meteorologie und Klimaforschung, Karlsruhe, Germany \\ ${ }^{3}$ LERMA-IPSL, Sorbonne Universités, UPMC Univ. Paris 6, Observatoire de Paris, \\ PSL Research University, CNRS, Paris, France
}

Correspondence to: Bastiaan Jonkheid (jonkheid@ gmail.com)

Received: 25 April 2016 - Published in Atmos. Meas. Tech. Discuss.: 14 June 2016

Revised: 25 August 2016 - Accepted: 31 August - Published: 15 December 2016

\begin{abstract}
A method for retrieval of ${ }^{18} \mathrm{O}$-substituted isotopomers of $\mathrm{O}_{3}$ in the stratosphere with the Michelson Interferometer for Passive Atmospheric Sounding (MIPAS) is presented. Using a smoothing regularisation constraint, volume mixing ratio profiles are retrieved for the main isotopologue and the symmetric and asymmetric isotopomers of singly substituted $\mathrm{O}_{3}$. For the retrieval of the heavy isotopologues, two microwindows in the MIPAS A band (685$\left.970 \mathrm{~cm}^{-1}\right)$ and six in the $\mathrm{AB}$ band $\left(1020-1170 \mathrm{~cm}^{-1}\right)$ are used. As the retrievals are performed as perturbations on the previously retrieved a priori profiles, the vertical resolution of the individual isotopomer profiles is very similar, which is important when calculating the ratio between two isotopomers. The performance of the method is evaluated using 1044 vertical profiles recorded with MIPAS on 1 July 2003. The mean values are separated by latitude bands, along with estimates of their uncertainties. The asymmetric isotopomer shows a mean enrichment of $\sim 8 \%$, with a vertical profile that increases up to $33 \mathrm{~km}$ and decreases at higher altitudes. This decrease with altitude is a robust result that does not depend on retrieval settings, and it has not been reported clearly in previously published datasets. The symmetric isotopomer is considerably less enriched, with mean values around $3 \%$ and with a large spread. In individual retrievals the uncertainty of the enrichment is dominated by the measurement noise $(2-4 \%)$, which can be reduced by averaging multiple retrievals; systematic uncertainties linked to the retrieval are generally small at $\sim 0.5 \%$, but this is likely underestimated because the uncertainties in key spectroscopic parameters are unknown. The variabilities in the retrieval results are largest for the Southern Hemisphere.
\end{abstract}

\section{Introduction}

The abundance of the heavy oxygen isotopes ${ }^{17} \mathrm{O}$ and ${ }^{18} \mathrm{O}$ in stratospheric $\mathrm{O}_{3}$ is unusually large compared to ambient $\mathrm{O}_{2}$. This isotopic enrichment was first discovered for ${ }^{18} \mathrm{O}$ by in situ mass spectrometer measurements by Mauersberger (1981). Laboratory experiments by Thiemens and Heidenreich (1983) found that the isotopic enrichment does not follow the common mass-dependent fractionation law. Rather, enrichments of ${ }^{17} \mathrm{O}$ and ${ }^{18} \mathrm{O}$ are of almost equal magnitude, i.e. mass-independent fractionation. This unique isotopic signature, called the ozone isotope effect, is a useful tracer for the role of $\mathrm{O}_{3}$ in atmospheric chemistry, where it has been shown to affect the isotopic composition of, for example, $\mathrm{CO}_{2}$ (Yung et al., 1991), $\mathrm{CO}$ (Röckmann et al., 1998) and $\mathrm{N}_{2} \mathrm{O}$ (McLinden et al., 2003).

Since the discovery over 30 years ago, these findings have been confirmed by further mass spectrometer measurements of atmospheric samples (Krankowsky et al., 2007), and by high-resolution spectroscopy using surface-based total-column measurements (Rinsland et al., 1985; Meier and Notholt, 1996), balloon-borne instruments (Abbas et al., 1987; Goldman et al., 1989; Johnson et al., 2000; Haverd et al., 2005), and space-based spectrometers (Irion et al., 1996; Piccolo et al., 2009; Sato et al., 2014). Laboratory research indicated that the observed isotopic enrichment is primarily controlled by unusually strong isotope effects associated with the $\mathrm{O}_{3}$ formation reaction (Morton et al., 1990):

$\mathrm{O}+\mathrm{O}_{2} \leftrightharpoons \mathrm{O}_{3}^{*} \stackrel{\mathrm{M}}{\rightarrow} \mathrm{O}_{3}$. 
Here, $\mathrm{M}$ is a bath gas molecule that stabilises the excited complex $\mathrm{O}_{3}^{*}$. It was also found that the enrichment is mainly located in the asymmetric isotopomers (Mauersberger et al., 1993). The rate coefficients of many individual isotopic combinations in reaction (R1) have been measured (Anderson et al., 1997; Janssen et al., 1999; Mauersberger et al., 1999), and it was found that there is a strong dependence of the rate coefficient of (R1) on the change in zero-point energy in the equivalent exchange reaction $\mathrm{O}+\mathrm{O}_{2} \rightarrow \mathrm{O}_{3}^{*} \rightarrow \mathrm{O}_{2}+\mathrm{O}$ (Janssen et al., 2001). Theoretical calculations suggest that the enrichment of the asymmetric isotopomers can likely be explained by a non-statistical behaviour of the excited complex, making it more stable and less likely to spontaneously dissociate (Hathorn and Marcus, 1999; Gao and Marcus, 2002). The fractionation of the formation rate coefficient depends strongly on pressure and temperature. The formation reaction can explain the magnitude and variability of the enrichment observed in the lower stratosphere, where $\mathrm{O}_{3}$ is enriched by $8-10 \%$, and the enrichments show a positive correlation with temperature.

In addition to the ozone formation reaction, the photolysis of ozone in the reaction

$\mathrm{O}_{3}+\mathrm{h} v \rightarrow \mathrm{O}_{2}+\mathrm{O}$

also causes an enrichment of the heavy isotopologues by preferential destruction of the lighter ones. Initial evidence for this comes from laboratory experiments (Bhattacharya and Thiemens, 1988; Chakraborty and Bhattacharya, 2003), and was recently substantiated by measurements where photolytic $\mathrm{O}_{3}$ removal could be analytically separated from chemical removal (Früchtl et al., 2015a). Wavelengthdependent isotope effects in $\mathrm{O}_{3}$ photolysis are also suggested by theoretical calculations (Miller et al., 2005; Liang et al., 2006; Ndengué et al., 2014), but the agreement of these calculations with new high-precision measurements is relatively poor (Früchtl et al., 2015b). Nevertheless, isotope effects in photolysis have been suggested as an explanation for the high enrichments found by balloon measurements in the upper stratosphere (Haverd et al., 2005; Krankowsky et al., 2007), where the effects of the formation reaction fall short of the observed enrichments by $2-4 \%$.

The isotopic composition is commonly reported in delta notation, where the heavy-to-light isotope ratio $R$ in a sample is compared to the same ratio in a reference material. The enrichment $\delta$ of ${ }^{k} \mathrm{O}(k=17,18)$ is then defined as

$\delta\left({ }^{k} \mathrm{O}\right)=\left(\frac{R\left({ }^{k} \mathrm{O}\right)_{\mathrm{obs}}}{R\left({ }^{k} \mathrm{O}\right)_{\mathrm{ref}}}-1\right)$.

Since the isotope effects for $\mathrm{O}_{3}$ are very large, they are often reported in percent $(\%)$ rather than parts per thousand $(\%)$, and this convention is followed in the present paper. The primary international reference ratio $R\left({ }^{n} \mathrm{O}\right)$ ref is Vienna Standard Mean Ocean Water (VSMOW; $R\left({ }^{17} \mathrm{O}\right)_{\text {VSMOW }}=$ $\left.7.799 \times 10^{-4}, R\left({ }^{18} \mathrm{O}\right)_{\text {VSMOW }}=2.00520 \times 10^{-3}\right)$, but in studies of the $\mathrm{O}_{3}$ isotopic composition the ratio of atmospheric $\mathrm{O}_{2}$ is often used. Atmospheric $\mathrm{O}_{2}$ is enriched by $1.208 \%$ in ${ }^{17} \mathrm{O}$ and by $2.388 \%$ in ${ }^{18} \mathrm{O}$ with respect to VSMOW (Barkan and Luz, 2005), and this is the standard used throughout this paper.

The enrichments derived in this paper are calculated for singly ${ }^{18} \mathrm{O}$-substituted $\mathrm{O}_{3}$, i.e. an ozone molecule consisting of two ${ }^{16} \mathrm{O}$ isotopes and one ${ }^{18} \mathrm{O}$ isotope. The isotopologues are labelled by their total mass, so that ${ }^{48} \mathrm{O}_{3}$ denotes an ozone molecule consisting of three ${ }^{16} \mathrm{O}$ isotopes and ${ }^{50} \mathrm{O}_{3}$ an ozone molecule with two ${ }^{16} \mathrm{O}$ isotope and one ${ }^{18} \mathrm{O}$ isotope. The enrichment of ${ }^{50} \mathrm{O}_{3}$ is then calculated from the ratio $R_{\text {obs }}\left({ }^{50} \mathrm{O}_{3}\right)=\frac{\left.{ }^{[0} \mathrm{O}_{3}\right]}{\left(3\left[{ }^{48} \mathrm{O}_{3}\right]\right)}$. The statistical factor 3 in the denominator accounts for the three positions where the ${ }^{18} \mathrm{O}$ atom can reside in the molecule, and allows the observed ratio to be compared to the reference, which is defined as the atomic ratio. Where applicable, the symmetric and asymmetric isotopomers of ${ }^{50} \mathrm{O}_{3}$ are indicated with the prefix $\mathrm{s}$ or a; i.e. $\mathrm{s}-{ }^{50} \mathrm{O}_{3}$ denotes ${ }^{16} \mathrm{O}^{18} \mathrm{O}^{16} \mathrm{O}$ and $\mathrm{a}-{ }^{50} \mathrm{O}_{3}$ denotes ${ }^{18} \mathrm{O}^{16} \mathrm{O}^{16} \mathrm{O}$. Enrichments of $\mathrm{a}-{ }^{50} \mathrm{O}_{3}$ include a statistical factor of 2 in the denominator of $R_{\text {obs }}$.

In this paper, satellite retrievals of $\delta\left(\mathrm{a}-{ }^{50} \mathrm{O}_{3}\right)$ and $\delta\left(\mathrm{s}-{ }^{50} \mathrm{O}_{3}\right)$ derived from the Michelson Interferometer for Passive Atmospheric Sounding (MIPAS) instrument on Envisat are presented. The purpose is to investigate whether and how the MIPAS observations can be used to provide independent data on ozone enrichment in the middle and upper stratosphere, and to detect and quantify possible temporal and geographical variations. For validation, these enrichments are compared to previously published results from the balloon-based thermal emission Fourier transform infrared (FTIR) spectra of Johnson et al. (2000), the balloon-based solar FTIR spectra of Haverd et al. (2005), the space-based ATMOS solar spectra of Irion et al. (1996), and the space-based SMILES thermal emission spectra by Sato et al. (2014); the total enrichment of ${ }^{50} \mathrm{O}_{3}$ is compared to the presumably highest precision mass spectrometer data of Krankowsky et al. (2007).

This paper is structured as follows: the description of the data and the retrieval procedure, including the error analysis, is given in Sect. 2. The results are discussed in Sect. 3, and conclusions are presented in Sect. 4.

\section{Data and retrieval}

\subsection{MIPAS}

The Michelson Interferometer for Passive Atmospheric Sounding (MIPAS) is a limb-sounding spectrometer on the Envisat satellite. It sampled the mid-infrared region between 685 and $2410 \mathrm{~cm}^{-1}$, with a spectral resolution of $0.025 \mathrm{~cm}^{-1}$ during the first 2 years of observations (from June 2002 to March 2004). Due to problems with the interferometer mir- 
ror slide, the instrument operated on a reduced spectral resolution of $0.0625 \mathrm{~cm}^{-1}$ after this period; operations ended with the loss of contact with Envisat in April 2012. An overview of MIPAS and its capabilities is given by Fischer et al. (2008).

There are several processors that retrieve ozone volume mixing ratios (VMRs) from MIPAS level $1 \mathrm{~b}$ data; an overview and intercomparison is given by Laeng et al. (2015). These algorithms differ in the microwindows and regularisation technique used, but yield similar results. In this work, the retrieval processor developed by KIT-IMK (Karlsruhe) and IAA/CSIC (Granada) is used. A detailed description is given in von Clarmann et al. (2003); its performance on ozone retrievals was studied in detail by Glatthor et al. (2006). Validation studies performed by Steck et al. (2007) and Laeng et al. (2014) showed that MIPAS ozone retrievals have realistic error estimates, and suffer from only small biases of 5-20\% (depending on altitude and reference instrument).

MIPAS data have been used to retrieve the ozone isotopologues ${ }^{49} \mathrm{O}_{3}$ and ${ }^{50} \mathrm{O}_{3}$ by Piccolo et al. (2009). There was generally a good agreement between the MIPAS Envisatderived enrichments and those obtained from FIRS-2 (Johnson et al., 2000) and MIPAS-B (Friedl-Vallon et al., 2004) for $\mathrm{a}-{ }^{50} \mathrm{O}_{3}$ and $\mathrm{s}-{ }^{50} \mathrm{O}_{3}$; the enrichments for ${ }^{49} \mathrm{O}_{3}$ were higher than expected from either theory or FIRS-2 observations. In the current paper, the latter isotopologue is not examined because its weak spectral lines make it hard to quantify accurately; rather, special attention is given to the enrichment profiles of ${ }^{50} \mathrm{O}_{3}$ for different latitude bands.

\subsection{Retrieval set-up}

To retrieve the volume mixing ratios (VMRs) of ${ }^{48} \mathrm{O}_{3}$, $\mathrm{a}-{ }^{50} \mathrm{O}_{3}$, and $\mathrm{s}-{ }^{50} \mathrm{O}_{3}$, contained in the atmospheric state vector $\boldsymbol{x}$, from the measured irradiances $\boldsymbol{y}$, the retrieval processor iteratively minimises the least squares equation (von Clarmann et al., 2003):

$\chi^{2}=(\boldsymbol{y}-\boldsymbol{f}(\boldsymbol{x}))^{T} \mathbf{S}_{y}^{-1}(\boldsymbol{y}-\boldsymbol{f}(\boldsymbol{x}))+\left(\boldsymbol{x}-\boldsymbol{x}_{a}\right)^{T} \mathbf{R}\left(\boldsymbol{x}-\boldsymbol{x}_{a}\right)$,

where $f$ is the forward radiative transfer model, $\mathbf{S}_{y}$ is the error covariance matrix of the observations, $\boldsymbol{x}_{a}$ is the a priori state vector, and $\mathbf{R}$ is the regularisation matrix. This procedure is structurally similar to the scheme described by Rodgers (2000). The forward model is the Karlsruhe Optimised and Precise Radiative transfer Algorithm (KOPRA; Stiller et al., 2002). The regularisation matrix is of the form $\mathbf{R}=\mathbf{T}_{1}^{T} \boldsymbol{\Lambda} \mathbf{T}_{1}+\mathbf{D}$, where $\mathbf{T}_{1}$ is a first-order derivative operator and $\boldsymbol{\Lambda}$ is a diagonal matrix containing weights for each altitude step (cf. Tikhonov, 1963; Steck, 2002). This term maps the shape (but not the values) of the a priori $\mathrm{O}_{3}$ profile to the heavy $\mathrm{O}_{3}$ profile when the measurement does not resolve the full structure of the latter. $\mathbf{D}$ is a diagonal matrix, which is usually zero everywhere except for the elements referring to the topmost altitudes of 100 and $120 \mathrm{~km}$; it forces the ozone
Table 1. Microwindows used in this study. The first two are in the A band $\left(685-970 \mathrm{~cm}^{-1}\right)$, the remaining six in the $\mathrm{AB}$ band $(1020$ $\left.1170 \mathrm{~cm}^{-1}\right)$.

\begin{tabular}{rr}
\hline $\begin{array}{r}\text { Spectral range } \\
\left(\mathrm{cm}^{-1}\right)\end{array}$ & $\begin{array}{r}\text { Vertical extent } \\
(\mathrm{km})\end{array}$ \\
\hline $713.800-714.500$ & $18-30$ \\
$960.950-963.950$ & $18-36$ \\
$1020.725-1023.650$ & $6-68$ \\
$1037.825-1038.375$ & $52-68$ \\
$1042.125-1042.875$ & $47-68$ \\
$1043.225-1044.675$ & $6-39$ \\
$1053.975-1055.350$ & $18-68$ \\
$1088.000-1091.000$ & $6-68$ \\
\hline
\end{tabular}

VMRs at these altitudes to be close to zero. The a priori values $\boldsymbol{x}_{a}$ come from MIPAS IMK/IAA V5H ozone profiles. For ${ }^{48} \mathrm{O}_{3}$ these exact profiles are used, while for ${ }^{50} \mathrm{O}_{3}$ they are scaled according to $\delta\left({ }^{50} \mathrm{O}_{3}\right)=0$ with respect to the standard used in the HITRAN database; in terms of the standard adopted in the present paper, this is a prior enrichment of $-3.02 \%$. Terms that account for continuum radiation and radiance offset due to calibration errors are retrieved along with the atmospheric state vector $\boldsymbol{x}$.

Instead of investigating the full MIPAS spectrum for each retrieval, a microwindow approach is used to only analyse the spectral regions that supply information on ${ }^{48} \mathrm{O}_{3}$ and ${ }^{50} \mathrm{O}_{3}$ abundances (cf. von Clarmann and Echle, 1998). A set of eight microwindows is utilised, based on the set of Piccolo et al. (2009) with slight modifications; this set contains two microwindows in the A band $\left(685-970 \mathrm{~cm}^{-1}\right)$ and six in the AB band (1020-1170 $\mathrm{cm}^{-1}$ ); see Table 1. Although including the $\mathrm{AB}$ band may lead to biases in retrievals of ${ }^{48} \mathrm{O}_{3}$ (see Laeng et al., 2014, 2015, for more information), the AB band contains many suitable emission lines for the retrieval of ${ }^{50} \mathrm{O}_{3}$. By excluding the $\mathrm{AB}$ band both $\mathrm{a}-{ }^{50} \mathrm{O}_{3}$ and $\mathrm{s}-{ }^{50} \mathrm{O}_{3}$ are limited to 3 degrees of freedom (defined as the trace of the averaging kernel; see Rodgers, 2000), while including the $\mathrm{AB}$ band increases this number to 6 . The precision of the retrievals also suffers when the $\mathrm{AB}$ band data are disregarded, with standard deviations that are a factor of 4 larger. Thus, the gain in isotopic information by including the spectral lines in the MIPAS AB band outweighs the problem of a possible bias between the $\mathrm{A}$ and $\mathrm{AB}$ bands. Conversely, the $\mathrm{A}$ band includes many $s-{ }^{50} \mathrm{O}_{3}$ lines, so this band cannot be ignored without a significant loss of information.

From the resulting VMRs of ${ }^{48} \mathrm{O}_{3}, \mathrm{a}-{ }^{50} \mathrm{O}_{3}$, and $\mathrm{s}-{ }^{50} \mathrm{O}_{3}$, the isotopic enrichments $\delta\left(\mathrm{a}-{ }^{50} \mathrm{O}_{3}\right)$ and $\delta\left(\mathrm{s}-{ }^{50} \mathrm{O}_{3}\right)$ are calculated. The total enrichment, used for comparison with mass spectrometer data, is then given by $\delta\left({ }^{50} \mathrm{O}_{3}\right)=$ $\left(2 \delta\left(\mathrm{a}-{ }^{50} \mathrm{O}_{3}\right)+\delta\left(\mathrm{s}-{ }^{50} \mathrm{O}_{3}\right)\right) / 3$. The relevant isotopomers are retrieved using an existing MIPAS ozone product as a priori profiles, appropriately scaled in the case of ${ }^{50} \mathrm{O}_{3}$; thus, the results can be interpreted as a perturbation on these a priori 
profiles. This means that matching the vertical resolution of the different isotopomers, normally required to avoid mixing of information from different altitudes, is not an important issue. The regularisation parameters were chosen in such a way that the following is true.

- The precision of the resulting $\delta\left({ }^{50} \mathrm{O}_{3}\right)$ profiles is optimised. In practice this means that the regularisation is strong enough that it results in smooth VMR profiles.

- The number of degrees of freedom of the ${ }^{50} \mathrm{O}_{3}$ retrievals is maximised, given the above restriction.

- The vertical resolutions of the ${ }^{48} \mathrm{O}_{3}$ retrievals are similar to those of the heavy isotopomers; vertical resolution is defined here as the full width at half maximum of the averaging kernels. This means that the ${ }^{48} \mathrm{O}_{3}$ profiles are regularised more strongly than would be necessary for an independent retrieval, but this way the ratio of the VMRs makes physical sense while the sensitivity loss reported by Worden et al. (2012) is avoided.

\subsection{Error analysis}

With the retrieval set-up in place, the uncertainties in the profiles of the VMRs and their covariances are calculated. The following sources of uncertainties in the retrievals are considered:

- measurement noise, based on instrumental parameters;

- uncertainties in the profiles of interfering species; gases considered here are $\mathrm{H}_{2} \mathrm{O}, \mathrm{CO}_{2}, \mathrm{~N}_{2} \mathrm{O}, \mathrm{CH}_{4}, \mathrm{SO}_{2}, \mathrm{NO}_{2}$, $\mathrm{NH}_{3}, \mathrm{HNO}_{3}, \mathrm{HCN}, \mathrm{C}_{2} \mathrm{H}_{2}, \mathrm{C}_{2} \mathrm{H}_{6}, \mathrm{COF}_{2}, \mathrm{CFC}-11$, CFC-12, CFC-22, SF 6 , CFC-113, $\mathrm{N}_{2} \mathrm{O}_{5}, \mathrm{ClONO}_{2}$ and $\mathrm{CH}_{3} \mathrm{COCH}_{3}$; the uncertainties are taken from MIPAS retrievals of these species;

- uncertainties in the temperature profile, and in horizontal temperature gradients; the temperature is a retrieved quantity, and the uncertainty in the retrieval is used here; for the horizontal gradient, a fixed value is assumed (see Table 2);

- uncertainties in the spectroscopic data in the HITRAN database; it should be noted that for $a-{ }^{50} \mathrm{O}_{3}$ and $\mathrm{s}-{ }^{50} \mathrm{O}_{3}$ several critical parameters, such as line position and intensity, have no uncertainties given in the HITRAN database at the frequencies considered here; this component of the systematic uncertainty is therefore underestimated in the calculations;

- uncertainties in the instrumental parameters: line of sight, residual spectral shift, gain calibration, and instrumental line shape; the assumed values for these uncertainties are given in Table 2.
Table 2. Uncertainties in retrieval parameters. The temperature gradient, line of sight tangent height, and spectral shift uncertainties are given in absolute terms, while the gain calibration and instrumental line shape uncertainties are relative.

\begin{tabular}{lc}
\hline Parameter & Uncertainty \\
\hline$T$ gradient & $0.01 \mathrm{~K} \mathrm{~km}^{-1}$ \\
Line of sight & $0.15 \mathrm{~km}$ \\
Spectral shift & $5 \times 10^{-4} \mathrm{~cm}^{-1}$ \\
Gain & $1 \%$ \\
Line shape & $3 \%$ \\
\hline
\end{tabular}

A further source of uncertainty is the smoothing error, which accounts for the difficulty in retrieving small-scale variations. Because most of the vertical variation in the VMR profiles is already contained in the a priori information, and the focus is on the enrichment profiles, which are expected to show only limited variations, the smoothing error is not considered significant here. Similarly, errors due to non-local thermal equilibrium effects are assumed to be irrelevant for the altitudes considered in this paper.

The uncertainties due to these parameters are calculated for 128 example geolocations, distributed over five latitude bands: polar $(\mathrm{N}), 60-90^{\circ} \mathrm{N}$; midlatitude $(\mathrm{N}), 30-60^{\circ} \mathrm{N}$; tropical, $30-30^{\circ} \mathrm{N}$; midlatitude (S), 30-60 $\mathrm{S}$; and polar (S), 60$90^{\circ} \mathrm{S}$. The calculations were performed for retrievals from 1 July 2003; 16 for daytime retrievals and 16 for night-time retrievals except in the polar latitude bands. Following Glatthor et al. (2006), all errors are assumed to decrease when averaging a large number of profiles, except those due to uncertainties in line spectroscopic data and instrumental line shape.

The errors in the VMRs due to measurement noise are given by

$\mathbf{S}_{\text {noise }}=\mathbf{G S}_{y} \mathbf{G}^{T}$,

where $\mathbf{G}$ is the gain matrix $\mathbf{G}=\left(\mathbf{K}_{x}^{T} \mathbf{S}_{y}^{-1} \mathbf{K}_{x}+\mathbf{R}\right)^{-1} \mathbf{K}_{x}^{T} \mathbf{S}_{y}^{-1}$ and $\mathbf{K}_{x}$ is the Jacobian $\mathbf{K}_{x}=\mathrm{d} \boldsymbol{y} / \mathrm{d} \boldsymbol{x}$.

The errors due to retrieval parameter uncertainties are given by

$\mathbf{S}_{\text {parameter }}=\mathbf{G K}_{b} \mathbf{S}_{b} \mathbf{K}_{b}^{T} \mathbf{G}^{T}$,

where $\mathbf{K}_{b}$ is the Jacobian $\mathbf{K}_{b}=\mathrm{d} \boldsymbol{y} / \mathrm{d} \boldsymbol{b}$ and $\boldsymbol{b}$ is a vector containing the retrieval parameters, with associated uncertainties $\mathbf{S}_{b}$.

The total VMR error is then

$\mathbf{S}_{\mathrm{VMR}}=\mathbf{S}_{\text {noise }}+\mathbf{S}_{\text {parameter }}$

The errors in the derived enrichments of $\mathrm{s}^{50}{ }^{50} \mathrm{O}_{3}$ are given by (cf. Steinwagner et al., 2007)

$\mathbf{S}_{\delta\left(\mathrm{s}-{ }^{50} \mathrm{O}_{3}\right)}=\mathbf{J}_{\mathrm{s}} \mathbf{S}_{\mathrm{s}} \mathbf{J}_{\mathrm{s}}^{T}$, 
where for a given altitude level $i$ :

$$
\begin{aligned}
& \mathbf{J}_{\mathrm{s}, i}=\left(\frac{\partial \delta\left(\mathrm{s}-{ }^{50} \mathrm{O}_{3}\right)_{i}}{\partial \operatorname{VMR}\left({ }^{48} \mathrm{O}_{3}\right)_{i}}, \frac{\partial \delta\left(\mathrm{s}-{ }^{50} \mathrm{O}_{3}\right)_{i}}{\partial \operatorname{VMR}\left(\mathrm{s}-{ }^{50} \mathrm{O}_{3}\right)_{i}}\right) \\
& =\left(\frac{-\operatorname{VMR}\left(\mathrm{s}-{ }^{50} \mathrm{O}_{3}\right)_{i}}{R\left({ }^{18} \mathrm{O}\right)_{\text {ref }} \operatorname{VMR}\left({ }^{48} \mathrm{O}_{3}\right)_{i}^{2}}, \frac{1}{R\left({ }^{18} \mathrm{O}\right)_{\text {ref }} \operatorname{VMR}\left({ }^{48} \mathrm{O}_{3}\right)_{i}}\right)
\end{aligned}
$$

$\mathbf{S}_{\mathrm{S}}=\left(\begin{array}{cc}\mathbf{S}_{48} & \mathbf{S}_{48},{ }_{\mathrm{s}-}{ }^{50} \mathrm{O}_{3} \\ \mathbf{S}_{\mathrm{S}-50} \mathrm{O}_{3},{ }^{48} \mathrm{O}_{3} & \mathbf{S}_{\mathrm{s}-}{ }^{50} \mathrm{O}_{3}\end{array}\right)$

Here, the matrices $\mathbf{S}_{48}$ and $\mathbf{S}_{\mathrm{s}-50} \mathrm{O}_{3}$ are the subsets of $\mathbf{S}_{\mathrm{VMR}}$ that contain the covariance matrices of $\operatorname{VMR}\left({ }^{48} \mathrm{O}_{3}\right)$ and $\operatorname{VMR}\left(\mathrm{s}-{ }^{50} \mathrm{O}_{3}\right)$, and the matrix $\mathbf{S}_{48},{ }_{\mathrm{s}-}{ }^{50} \mathrm{O}_{3}=\mathbf{S}_{\mathrm{s}^{-}-{ }^{50} \mathrm{O}_{3},{ }^{48} \mathrm{O}_{3}}$ accounts for error correlations in the retrievals. A similar expression is used for $\mathrm{a}-{ }^{50} \mathrm{O}_{3}$.

\section{Results and discussion}

\subsection{Uncertainty analysis}

The absolute measurement uncertainties, expressed in the units of the enrichments (i.e. as percentages), are shown in Fig. 1. It can be seen that for each individual retrieval the measurement noise is the dominant source of uncertainty, yielding an absolute uncertainty in the enrichment of 2-4\% in most latitude bands at altitudes where ozone is present in significant amounts. Measurement noise is lowest in the Northern Hemisphere and the tropics; in the southern latitude bands, particularly the polar band, it is higher, at $4 \%$. The random uncertainty due to retrieval parameters is smaller than the measurement noise, at 1-2\%; this component of the uncertainty is dominated by the uncertainty in the vertical CFC-113 profile and by uncertainties in the line of sight. The uncertainty due to overlap of CFC-113 spectral features is likely overestimated; these features are nearly constant in each microwindow, and any uncertainty would be compensated for by the fitting of continuum radiation. The total random uncertainty, and thus overall precision, is around $4 \%$, dependent on latitude and altitude.

The systematic errors caused by uncertainties in the spectroscopic parameters and the instrumental line shape are generally small at $0.5 \%$. However, it should be noted that, in the microwindows considered here, the magnitudes of the uncertainties in the spectroscopic data for ${ }^{50} \mathrm{O}_{3}$ are not given in the HITRAN database for several key parameters, such as line position and intensity. This is likely caused by the difficulty in distinguishing between the symmetric and asymmetric isotopomers, noted by Janssen (2005). Therefore, this uncertainty is underestimated here.
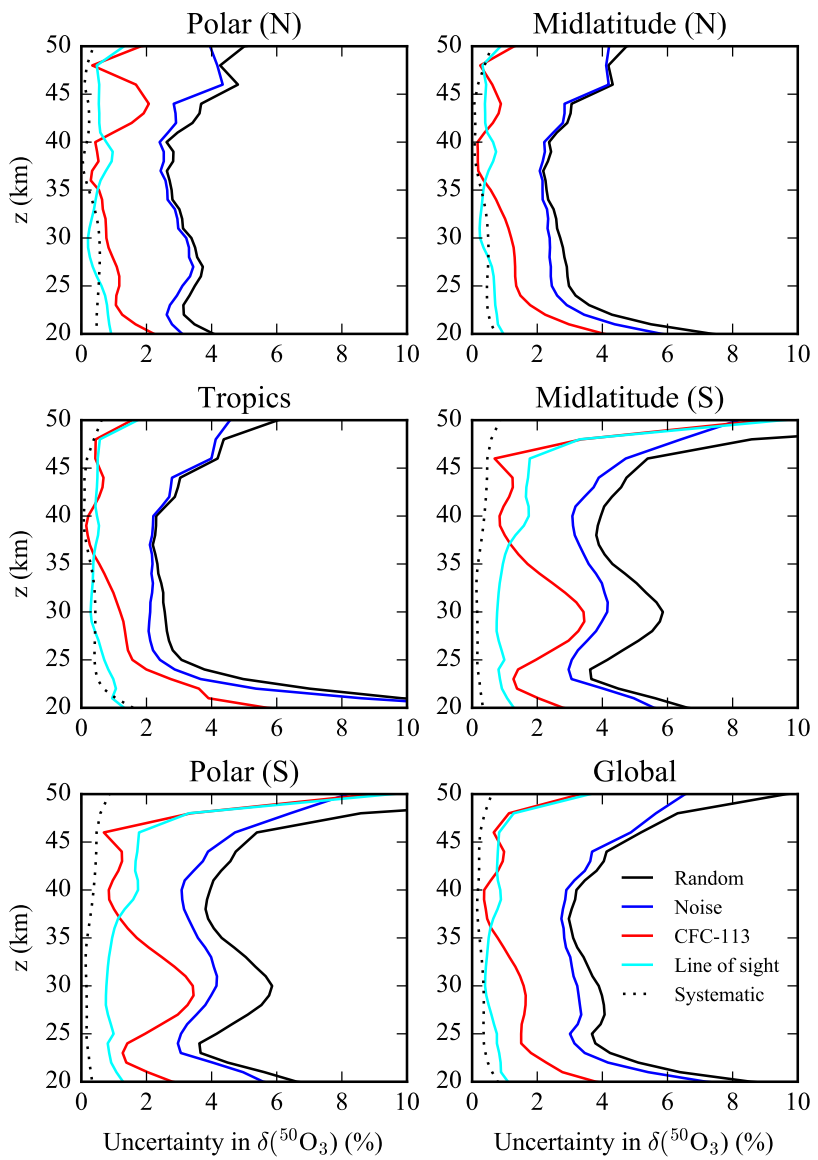

Figure 1. The absolute uncertainties in the retrievals of $\delta^{50} \mathrm{O}_{3}$. The total random uncertainty and its major components are shown: measurement noise, uncertainties in the CFC-113 profile, and uncertainties in the line of sight. The systematic uncertainties, which are not reduced by averaging over a large number of profiles, are also shown.

The uncertainties all increase sharply in all latitude bands at altitudes above $50 \mathrm{~km}$. While the uncertainty due to measurement noise can be reduced by averaging over a large number of profiles, the uncertainties in retrieval parameters, particularly instrumental parameters, will typically remain.

\subsection{Retrieved enrichments}

For all of the 1044 geolocations covered during 1 July 2003, the VMR profiles of ${ }^{48} \mathrm{O}_{3}, \mathrm{a}-{ }^{50} \mathrm{O}_{3}$, and $\mathrm{s}-{ }^{50} \mathrm{O}_{3}$ are retrieved. Of these, 66 are disregarded because the retrieval did not converge. Of the remaining 978 profiles, the altitude levels where the diagonal of the averaging kernel is less than a threshold value of 0.03 are disregarded because there is virtually no information for that level. On average, the retrievals have 6 degrees of freedom, with a vertical resolution of $6 \mathrm{~km}$ between 25 and $50 \mathrm{~km}$ of altitude (see Fig. 2).

The profiles of the mean total enrichments derived from these data are shown in Fig. 3, separated by latitude band. 

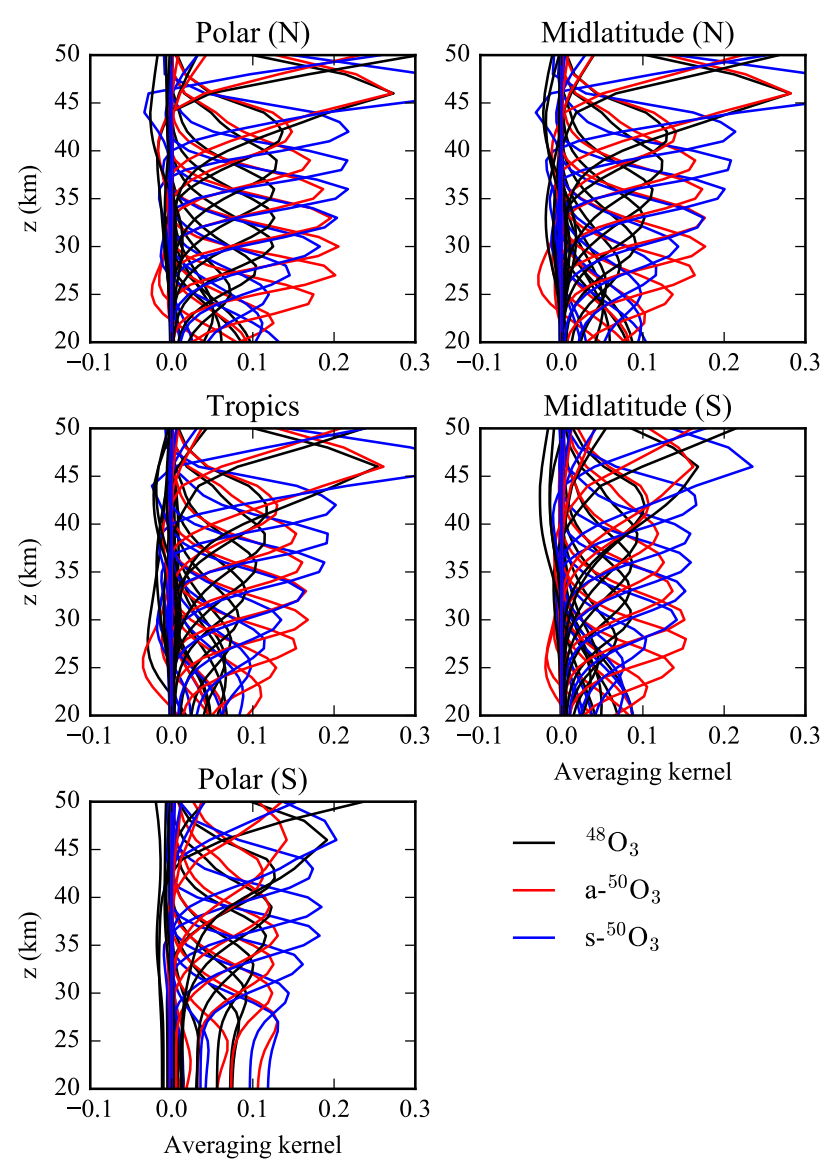

Figure 2. Mean averaging kernels of ${ }^{48} \mathrm{O}_{3}$ (black lines), a- ${ }^{50} \mathrm{O}_{3}$ (red lines), and $\mathrm{s}-{ }^{50} \mathrm{O}_{3}$ (blue lines). The averaging kernels are shown for one in every three vertical grid points for the sake of clarity.

The enrichments show values between 5 and $10 \%$ at altitudes between 20 and $50 \mathrm{~km}$. The shape of the enrichment profiles is consistent over the northern and tropical latitude bands, and is still discernible in the southern midlatitude band: there is a steady increase from 25 to $35 \mathrm{~km}$, a decrease until $40 \mathrm{~km}$, and an increase again until $48 \mathrm{~km}$. The standard deviation of the retrievals at $25-50 \mathrm{~km}$ is generally small $(4-5 \%)$ in the tropics and in the Northern Hemisphere, but much larger (up to $10 \%$ ) in the Southern Hemisphere. The standard deviation of the retrievals is comparable to the precision of the retrievals estimated in the uncertainty analysis. However in the southern midlatitude and polar bands, the standard deviation is up to twice the estimated precision, suggesting that there is some zonal variability in these latitude bands. In all latitude bands, the standard deviations tend to increase at altitudes $<25$ and $>50 \mathrm{~km}$. This is most likely caused by the difficulty in retrieving useful information at these altitudes, as seen in the averaging kernels in Fig. 2.

The means of all retrieved enrichments of a- ${ }^{50} \mathrm{O}_{3}$, $\mathrm{s}-{ }^{50} \mathrm{O}_{3}$, and for total ${ }^{50} \mathrm{O}_{3}$ are shown in Fig. 4. The enrich-
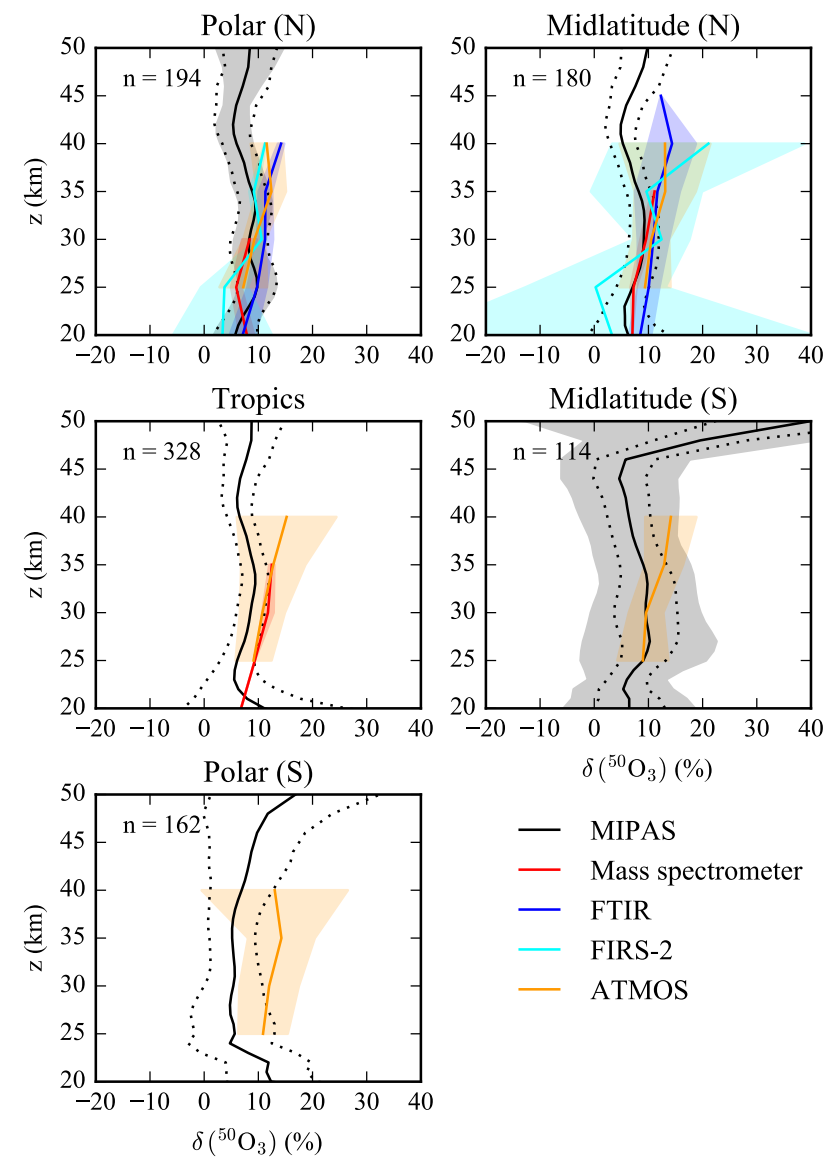

Figure 3. Total enrichments of ${ }^{50} \mathrm{O}_{3}$, separated by latitude band. The mean enrichments are shown (solid lines), as well as the total uncertainty in the retrievals (both random and systematic, dotted lines), and the standard deviations (shaded regions). The number of retrievals used in each band is indicated in the upper left corner. The mass spectrometer data of Krankowsky et al. (2007), the FTIR data of Haverd et al. (2005), the FIRS-2 data of Johnson et al. (2000), and the ATMOS data of Irion et al. (1996) are also shown. The previously published data are shown on a $5 \mathrm{~km}$ resolution grid, where the means and standard deviations are calculated for each altitude bin.

ment of the asymmetric isotopomer shows the same vertical trends as the total enrichment in Fig. 3. The standard deviation of the zonal means is relatively small and comparable in magnitude to the estimated precision of the retrievals (cf. Sect. 3.1). The symmetric isotopomer shows a very different vertical structure: at altitudes below $30 \mathrm{~km}$ the enrichment is around 5-8\%, of the same order as the asymmetric isotopomer, with a maximum at $27 \mathrm{~km}$. This maximum is primarily caused by high enrichments at northern latitudes. A similar maximum is visible in the standard deviation, but this originates from the larger variability in the Southern Hemisphere (cf. Figs. 3 and 5). Since this maximum is larger than the estimated precision, the zonal variability noted earlier likely comes from the symmetric iso- 

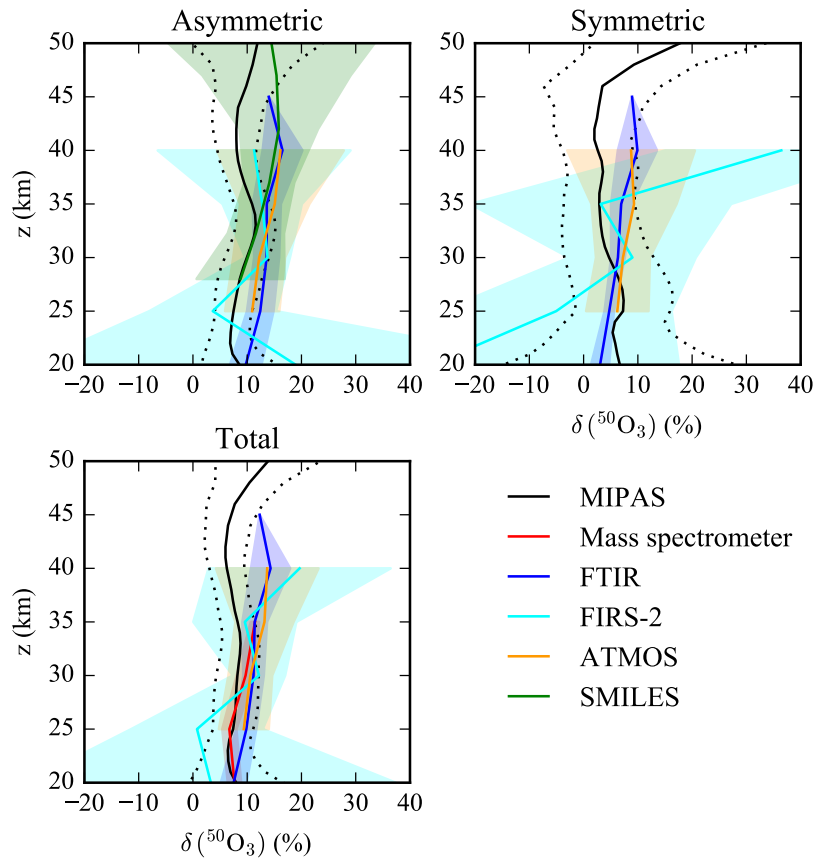

Figure 4. Averaged enrichments of $\mathrm{a}-{ }^{50} \mathrm{O}_{3}, \mathrm{~s}-{ }^{50} \mathrm{O}_{3}$, and total ${ }^{50} \mathrm{O}_{3}$. As in Fig. 3, the mean enrichments are shown by solid lines, the total uncertainty by the dotted lines, and the standard deviations by the shaded regions. The data retrieved in the current paper and previously measured values (see the caption of Fig. 3 for references), which are shown on a $5 \mathrm{~km}$ grid, are presented. The SMILES data of Sato et al. (2014), which is on its own grid of approximately $5 \mathrm{~km}$ vertical resolution, are also shown.

topomer. This would imply the occurrence of negative enrichments of $\mathrm{s}^{50} \mathrm{O}_{3}$ though, for which there is no known physical mechanism; a constant bias due to uncertainties in the spectroscopic parameters could explain this. At higher altitudes the enrichment is almost constant at a lower value of a few percent, and has lower standard deviations. The vertical trends of the total global enrichment profile resemble those of the northern latitude profiles in Fig. 3 and the enrichment profile of the asymmetric isotopomer, although the maximum at $35 \mathrm{~km}$ is less pronounced due to averaging with the Southern Hemisphere profiles that do not show this feature.

A more detailed look at the enrichment of both the asymmetric and symmetric isotopomers of ${ }^{50} \mathrm{O}_{3}$ as a function of latitude and altitude is given in Fig. 5. The enrichments of a $-{ }^{50} \mathrm{O}_{3}$ vary between 5 and $15 \%$, with a clear vertical structure that is visible at all latitudes north of $40^{\circ} \mathrm{S}$. This vertical structure is similar to that of $\delta\left({ }^{50} \mathrm{O}_{3}\right)$ shown in Fig. 3, with an increasing enrichment to $33 \mathrm{~km}$, followed by a decrease to $40 \mathrm{~km}$, and then a further increase until $47 \mathrm{~km}$. The standard deviation in the enrichments is a few percent at most altitudes. At latitudes south of $40^{\circ} \mathrm{S}$, the vertical structure is less pronounced, and standard deviations increase to 8-10\%. Under these conditions, little can be said about the vertical structure of the enrichment.
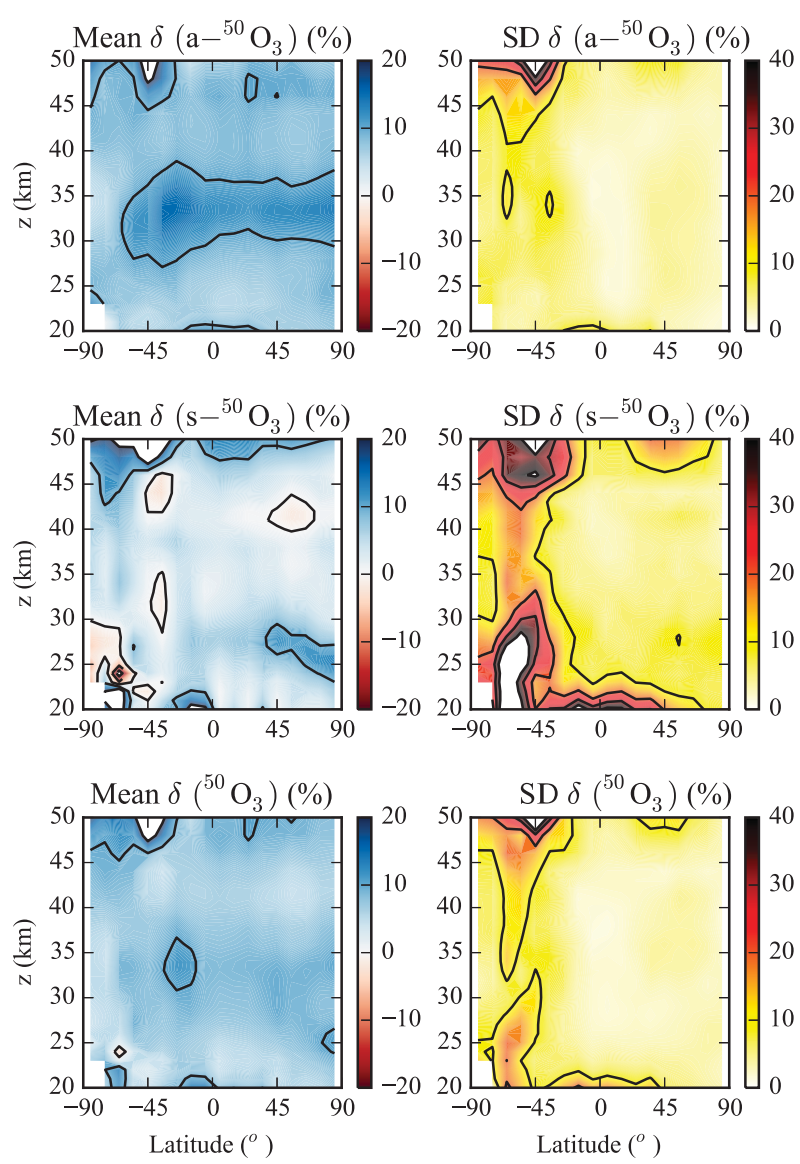

Figure 5. The mean retrieved enrichments of ${ }^{50} \mathrm{O}_{3}$ as a function of latitude and altitude (left column), and the standard deviation (SD) of the enrichments (right column). The upper and middle rows represent the asymmetric and symmetric isotopomers, respectively, and the lower row shows the total enrichment. The contours indicate $10 \%$ intervals.

It can be seen that $\mathrm{s}-{ }^{50} \mathrm{O}_{3}$ has enrichments of only a few percent at all latitudes and altitudes. Isotopic depletions occur at some places; as noted before, there is no known physical process that can cause these depletions, but a constant offset due to spectroscopic bias is possible. There is a maximum in the enrichment around $27 \mathrm{~km}$ in the Northern Hemisphere. Standard deviations are generally $5 \%$ or higher, and reach their maximum of $20-40 \%$ between 50 and $80^{\circ} \mathrm{S}$.

The vertical structure of the total enrichment combines the characteristics of the two isotopomers; it resembles that of $\mathrm{a}-{ }^{50} \mathrm{O}_{3}$, although the lower maximum is smeared out due to the lower altitude peak of $\delta\left(\mathrm{s}-{ }^{50} \mathrm{O}_{3}\right)$, while the second maximum is at $50 \mathrm{~km}$ rather than $47 \mathrm{~km}$ due to the sharp increase in the $\delta\left(\mathrm{s}-{ }^{50} \mathrm{O}_{3}\right)$ profile there. 


\subsection{Comparison with previously published data}

\subsubsection{Datasets}

The isotopic composition of stratospheric $\mathrm{O}_{3}$ has been studied extensively since its discovery. The most comprehensive datasets, used here for validation of the MIPAS data, are the space-based solar absorption spectra by the ATMOS Fourier transform infrared spectrometer (Irion et al., 1996); the balloon-borne thermal emission spectra by the FIRS-2 Fourier transform spectrometer (Johnson et al., 2000); the balloon-borne solar absorption spectra by the MkIV FTIR spectrometer (Haverd et al., 2005); the mass spectrometer data of Krankowsky et al. (2007); and the space-borne emission spectra by the SMILES submillimetre sounder (Sato et al., 2014).

The ATMOS dataset consists of observations from the Spacelab-3 mission in July 1973 and the Atlas-1, Atlas2, and Atlas-3 missions in March 1992, April 1993, and November 1994. It shows global average enrichments of $12 \pm 6 \%$ for a $-{ }^{50} \mathrm{O}_{3}$ and $7 \% \pm 7$ for $\mathrm{s}-{ }^{50} \mathrm{O}_{3}$ (using the isotopic standard adopted in this paper), with no discernible variations with latitude or altitude. The uncertainties indicate the standard deviation in the measurements.

The FIRS-2 dataset uses data of seven balloon flights between 1989 and 1997, launched from Fort Sumner, Daggett, and Fort Wainwright. The mean enrichments between 25 and $35 \mathrm{~km}$ of altitude are $12.2 \pm 1.0 \%$ for $\mathrm{a}-{ }^{50} \mathrm{O}_{3}$ and $6.1 \pm 1.8 \%$ for $\mathrm{s}-{ }^{50} \mathrm{O}_{3}$. Note that the uncertainties given here are the standard error of the mean as opposed to the standard deviation, which is typically larger. No significant variation with altitude is found.

The FTIR dataset uses data of seven balloon flights between 1997 and 2003, launched from Fort Wainwright, Esrange, and Fort Sumner. Mean enrichments of $13.8 \pm 2.9 \%$ and $7.0 \pm 2.6 \%$ are reported for $\mathrm{a}^{-50} \mathrm{O}_{3}$ and $\mathrm{s}-{ }^{50} \mathrm{O}_{3}$, respectively; it was not specified in the original publication whether these uncertainties denote standard deviations or standard errors. The absolute precision of the enrichments due to uncertainties in the retrieval parameters (temperature, pressure broadening coefficients, zero offset, and slant column integration) is estimated to be around $2 \%$. A pronounced vertical trend is attributed to photolytic enrichment. For two balloon flights, anomalously low enrichments are associated with a high stratospheric aerosol content due to the eruption of Mount Pinatubo.

The mass spectrometer data were collected from 11 balloon flights from Kiruna, Aire-sur-l'Adour, and Teresina between 1998 and 2005. These measurements show the highest precision of the datasets considered here; at high altitudes an absolute precision of $0.4 \%$ in the enrichment is reported. The use of mass spectrometry makes it impossible to distinguish $\mathrm{a}-{ }^{50} \mathrm{O}_{3}$ and $\mathrm{s}-{ }^{50} \mathrm{O}_{3}$, however. The measurements at midlatitude and equatorial latitudes show vertical trends that cannot be explained by the temperature effect in the formation re- action alone, and are ascribed to photolytic enrichment. The polar data show a seasonal trend that is consistent with the temperature.

The SMILES dataset was gathered at the International Space Station in February and March 2010. Only latitudes between 20 and $40^{\circ} \mathrm{N}$ were considered. It only contains enrichments for the $a-{ }^{50} \mathrm{O}_{3}$ isotopomer, but it covers higher altitudes (up to $52 \mathrm{~km}$ ) than the other datasets. The absolute systematic error in the enrichment varies between 4 and $6 \%$ at altitudes between 25 and $45 \mathrm{~km}$. This includes contributions of uncertainties in the air-broadening parameter and its temperature dependence, in the line intensity, in the antenna beam pattern, in the sideband separator characteristics, and in the antenna response function. The vertical variation of the enrichment is found to be linked with variations in temperature.

\subsubsection{By latitude band}

In the Northern Hemisphere there is generally good agreement between the MIPAS-derived enrichments and previously published data (see Fig. 3). In the polar latitude band there is a slight discrepancy between MIPAS and the mass spectrometer data of Krankowsky et al. (2007), but this is within the uncertainty limits of both datasets. Interestingly, the MIPAS data show a decrease at high altitudes $(>35 \mathrm{~km})$ that is not seen in other datasets.

In order to exclude that this decrease is due to an artefact of the retrieval procedure, several tests were performed.

- The vertical extent of the microwindows was expanded in order to increase the altitude range in which information is gathered. In particular, the A-band microwindows were extended up to $47 \mathrm{~km}$ in altitude. This did not result in a better agreement of the retrievals with previous independent data, and increased the number of retrievals with convergence problems.

- The altitude up to which a continuum term is fitted to the observations was increased from the previous value of $33 \mathrm{~km}$. The physical reason for this is the possible presence of aerosols in the middle and upper stratosphere (Neely et al., 2011). Some of the oscillations seen in the enrichment profiles decreased in amplitude by setting the cut-off for continuum regularisation to $50 \mathrm{~km}$; this value is used in the retrievals presented in this paper. Further increasing this altitude did not improve the retrievals and again caused convergence problems.

- A two-step retrieval was used with a different regularisation strategy. In the first step, only ${ }^{48} \mathrm{O}_{3}$ is retrieved. In the second step, only a- ${ }^{50} \mathrm{O}_{3}$ was retrieved, using as the a priori a- ${ }^{50} \mathrm{O}_{3}$ profile the result of the ${ }^{48} \mathrm{O}_{3}$ retrieval, scaled by $R_{\text {ref }}$, to which an enrichment of $10 \%$ was added. The regularisation matrix was limited to the matrix $\mathbf{D}$, with full diagonal values, while the vertical 
derivative term was set to zero. In this way, the regularisation procedure forces enrichment profiles to be close to a constant $10 \%$. The resulting enrichments showed a similar vertical structure as before, albeit with more noise since the resulting profiles are no longer smoothed in the regularisation.

The fact that the decrease above $35 \mathrm{~km}$ is retrieved in all these tests is reason to conclude that it is inherent in the MIPAS observations rather than an issue with the retrievals.

In the Southern Hemisphere the retrieved enrichments show comparatively large standard deviations. At midlatitudes there is a good agreement with the ATMOS-derived enrichments up to an altitude of $35 \mathrm{~km}$. Higher in the atmosphere the MIPAS enrichments decrease, while the ATMOS enrichments increase with height. At southern polar latitudes the MIPAS enrichments are lower than those of ATMOS at all altitudes. The standard deviations in the results are very large for both datasets, and there is a large overlap within 1 standard deviation.

\subsubsection{Global}

At altitudes below $33 \mathrm{~km}$ the global mean total enrichments of MIPAS are in good agreement with previous observations (cf. Fig. 4), particularly with the mass spectrometer data of Krankowsky et al. (2007). The disagreement with other datasets that is visible in the tropical and Northern Hemisphere latitude bands persists in the global average.

The global mean enrichments of $\mathrm{a}-{ }^{50} \mathrm{O}_{3}$ derived by MIPAS are generally in good agreement with previous observations. As is the case for total ${ }^{50} \mathrm{O}_{3}$ in the tropical and northern latitude bands, discussed above, the MIPAS global mean $\delta\left(\mathrm{a}-{ }^{50} \mathrm{O}_{3}\right)$ shows a decrease above $33 \mathrm{~km}$; other datasets also show a decrease with altitude, starting at $40 \mathrm{~km}$ for the FTIR dataset of Haverd et al. (2005) and the SMILES dataset of Sato et al. (2014), or at $30 \mathrm{~km}$ for the FIRS-2 dataset of Johnson et al. (2000). The ATMOS dataset of Irion et al. (1996) shows a steady increase up until the maximum retrieval altitude of $40 \mathrm{~km}$. Furthermore, a decreasing enrichment above $35 \mathrm{~km}$ is also predicted by photochemical models, caused by the large fractionation in the long-wavelength tail of the Hartley band (Liang et al., 2006; Ndengué et al., 2014). These models predict maxima at $35 \mathrm{~km}$ with amplitudes of $3 \%$ for $\mathrm{a}-{ }^{50} \mathrm{O}_{3}$ and $6 \%$ for $\mathrm{s}-{ }^{50} \mathrm{O}_{3}$.

The symmetric isotopomer profiles show large standard deviations below $30 \mathrm{~km}$ and above $45 \mathrm{~km}$, making comparison with other datasets problematic at those altitudes. Between 30 and $45 \mathrm{~km}$, the MIPAS enrichments are lower than those of the FTIR and ATMOS datasets; where the latter show the enrichments increasing with altitude, the former is steady or shows a slight decrease.

\section{Conclusions}

This paper presents MIPAS observations of the enrichments of ${ }^{18} \mathrm{O}$ in stratospheric ozone for 1 July 2003 . The retrieval set-up discussed here has projected absolute precisions of the enrichment of 4-6\% at all latitudes, and at most altitudes between 20 and $50 \mathrm{~km}$. The absolute systematic bias in the retrieved enrichments is $\sim 0.5 \%$, but this is an underestimate due to the unknown uncertainties in the line position and intensity of the ${ }^{50} \mathrm{O}_{3}$ lines used here. For individual retrievals, measurement noise is the main source of uncertainty, between 2 and $4 \%$ under most conditions but much higher (up to $8 \%$ ) at southern polar latitudes.

The mean MIPAS enrichments agree well with previous balloon-based and space-based observations at low altitudes $(<35 \mathrm{~km})$. At higher altitudes the MIPAS enrichments show a clear decrease. While other datasets also have decreasing enrichments with increasing altitude beyond some point, this decrease is usually much weaker and occurs at a different altitude. This feature is unlikely to be a retrieval artefact, and is probably inherent in the MIPAS data; it may be caused by photolytic effects, as suggested by theoretical models. The large standard deviations of the retrievals in the Southern Hemisphere, with a magnitude several times larger than the estimated accuracy, indicate variability in the profiles within a latitude band. The enrichment of the asymmetric isotopomer is typically higher $(\delta \sim 8-10 \%)$ than that of the symmetric isotopomer $(\delta \sim 2-3 \%)$.

In conclusion, isotope information can be obtained with acceptable precision from MIPAS measurements. Although systematic errors, in particular from spectroscopic uncertainties, are hard to quantify, such systematic effects are expected to remain constant in time, and likely also in space. Therefore, MIPAS isotope data can be used to study the spatial and temporal variability of the isotopic composition of stratospheric $\mathrm{O}_{3}$.

\section{Data availability}

The MIPAS VMR profiles, from which the enichments presented in this paper are derived, are available at http://www. projects.science.uu.nl/atmosphereclimate/Data.php (IMAU, 2016).

Acknowledgements. The authors want to thank Vanessa Haverd, Bill Irion, David Johnson, and Tomohiro Sato for providing their measurements of heavy ozone enrichment. This work was funded by the Netherlands Organisation for Scientific Research as project ALW-GO/12/05, Isotope measurements from space on stratospheric ozone (ISOZONE). The authors acknowledge provision of MIPAS level-1b data by the ESA.

Edited by: J. Worden

Reviewed by: two anonymous referees 


\section{References}

Abbas, M., Guo, J., Carli, B., Mencaraglia, F., Carlotti, M., and Nolt, I.: Heavy ozone distribution in the stratosphere from farinfrared observations, J. Geophys. Res., 92, 13231-13239, 1987.

Anderson, S., Hüsebusch, D., and Mauersberger, K.: Surprising rate coefficients for four isotopic variants of $\mathrm{O}+\mathrm{O}_{2}+\mathrm{M}$, J. Chem. Phys., 107, 5385-5392, 1997.

Barkan, E. and Luz, B.: High precision measurements of ${ }^{17} \mathrm{O} /{ }^{16} \mathrm{O}$ and ${ }^{18} \mathrm{O} /{ }^{16} \mathrm{O}$ ratios in $\mathrm{H}_{2} \mathrm{O}$, Rapid Commun. Mass Sp., 19, 3737-3742, 2005.

Bhattacharya, S. and Thiemens, M.: Isotopic fractionation in ozone decomposition, Geophys. Res. Lett., 15, 9-12, 1988.

Chakraborty, S. and Bhattacharya, S.: Oxygen isotopic fractionation during UV and visible light photodossociation of ozone, J. Chem. Phys., 118, 2164-2172, 2003.

Fischer, H., Birk, M., Blom, C., Carli, B., Carlotti, M., von Clarmann, T., Delbouille, L., Dudhia, A., Ehhalt, D., Endemann, M., Flaud, J. M., Gessner, R., Kleinert, A., Koopman, R., Langen, J., López-Puertas, M., Mosner, P., Nett, H., Oelhaf, H., Perron, G., Remedios, J., Ridolfi, M., Stiller, G., and Zander, R.: MIPAS: an instrument for atmospheric and climate research, Atmos. Chem. Phys., 8, 2151-2188, doi:10.5194/acp-8-2151-2008, 2008.

Friedl-Vallon, F., Maucher, G., Seefeldner, M., Trieschmann, O., Kleinert, A., Lengel, A., Keim, C., Oelhaf, H., and Fischer, H.: Design and characterization of the balloon-borne Michelson Interferometer for Passive Atmospheric Sounding (MIPAS-B2), Appl. Optics, 43, 3335-3355, 2004.

Früchtl, M., Janssen, C., and Röckmann, T.: Experimental study on isotope fractionation effects in visible photolysis of $\mathrm{O}_{3}$ and in the $\mathrm{O}+\mathrm{O}_{3}$ odd oxygen sink reaction, J. Geophys. Res., 120, 43984416, 2015a.

Früchtl, M., Janssen, C., Taraborrelli, D., Gromov, S., and Röckmann, T.: Wavelength-dependent isotope fractionation in visible light $\mathrm{O}_{3}$ photolysis and atmospheric implications, Geophys. Res. Lett., 42, 8711-8718, 2015b.

Gao, Y. and Marcus, R.: On the theory of the strange and unconventional isotopic effects in ozone formation, J. Chem. Phys, 116, 137-154, 2002.

Glatthor, N., von Clarmann, T., Fischer, H., Funke, B., GilLópez, S., Grabowski, U., Höpfner, M., Kellmann, S., Linden, A., López-Puertas, M., Mengistu Tsidu, G., Milz, M., Steck, T., Stiller, G. P., and Wang, D.-Y.: Retrieval of stratospheric ozone profiles from MIPAS/ENVISAT limb emission spectra: a sensitivity study, Atmos. Chem. Phys., 6, 2767-2781, doi:10.5194/acp-6-2767-2006, 2006.

Goldman, A., Murcray, F., Murcray, D., Kosters, J., Rinsland, C., Flaud, J., Camy-Peyret, C., and Barbe, A.: Isotopic abundances of stratopheric ozone from balloon-borne high-resolution infrared solar spectra, J. Geophys. Res., 94, 8467-8473, 1989.

Hathorn, B. and Marcus, R.: An intramolecular theory of the massindependent isotope effect for ozone. I., J. Chem. Phys., 111, 4087-4100, 1999.

Haverd, V., Toon, G., and Griffith, D.: Evidence for altitudedependent photolysis-induced ${ }^{18} \mathrm{O}$ isotopic fractionation in stratospheric ozone, Geophys. Res. Lett., 32, L22808, doi:10.1029/2005GL024049, 2005.

IMAU: IMAU-APCG measurements data, APCG Data Archive, Atmospheric Physics and Chemistry group of the Institute for Marine and Atmospheric Research Utrecht (IMAU), avail- able at: http://www.projects.science.uu.nl/atmosphereclimate/ Data.php, 2016.

Irion, F., Gunson, M., Rinsland, C., Yung, Y., Abrams, M., and Chang, A.: Heavy ozone enrichments from ATMOS infrared solar spectra, Geophys. Res. Lett., 23, 2377-2380, 1996.

Janssen, C.: Intramolecular isotope distribution in heavy ozone $\left({ }^{16} \mathrm{O}^{18} \mathrm{O}^{16} \mathrm{O}\right.$ and $\left.{ }^{16} \mathrm{O}^{16} \mathrm{O}^{18} \mathrm{O}\right)$, J. Geophys. Res., 110, D08308, doi:10.1029/2004JD005479, 2005.

Janssen, C., Guenther, J., Krankowsky, D., and Mauersberger, K.: Relative formation rates of ${ }^{50} \mathrm{O}_{3}$ and ${ }^{52} \mathrm{O}_{3}$ in ${ }^{16} \mathrm{O}-{ }^{18} \mathrm{O}$ mixtures, J. Chem. Phys., 111, 7179-7182, 1999.

Janssen, C., Guenther, J., Mauersberger, K., and Krankowsky, D.: Kinetic origin of the ozone isotope effect: a critical analysis of enrichments and rate coefficients, Phys. Chem. Chem. Phys., 3, 4718-4721, 2001

Johnson, D., Jucks, K., Traub, W., and Chance, K.: Isotopic compositionof stratospheric ozone, J. Geophys. Res., 105, 9025-9031, 2000.

Krankowsky, D., Lämmerzahl, P., Mauersberger, K., Janssen, C., Tuszon, B., and Röckmann, T.: Stratospheric ozone isotopic fractionations derived from collected samples, J. Geophys. Res., 112, D08301, doi:10.1029/2006JD007855, 2007.

Laeng, A., Grabowski, U., von Clarmann, T., Stiller, G., Glatthor, N., Höpfner, M., Kellmann, S., Kiefer, M., Linden, A., Lossow, S., Sofieva, V., Petropavlovskikh, I., Hubert, D., Bathgate, T., Bernath, P., Boone, C. D., Clerbaux, C., Coheur, P., Damadeo, R., Degenstein, D., Frith, S., Froidevaux, L., Gille, J., Hoppel, K., McHugh, M., Kasai, Y., Lumpe, J., Rahpoe, N., Toon, G., Sano, T., Suzuki, M., Tamminen, J., Urban, J., Walker, K., Weber, M., and Zawodny, J.: Validation of MIPAS IMK/IAA V5R_O3_224 ozone profiles, Atmos. Meas. Tech., 7, 3971-3987, doi:10.5194/amt-7-3971-2014, 2014.

Laeng, A., Hubert, D., Verhoelst, T., von Clarmann, T., Dinelli, B., Dudhia, A., Raspollini, P., Stiller, G., Grabowski, U., Keppens, A., Kiefer, M., Sofieva, V., Froidevaux, L., Walker, K., Lambert, J.-C., and Zehner, C.: The ozone climate change initiative: Comparison of four Level-2 processors for the Michelson Interferometer for Passive Atmospheric Sounding (MIPAS), Remote Sens. Environ., 162, 316-343, 2015.

Liang, M., Irion, F., Weibel, J., Miller, C., Blake, G., and Yung, Y.: Isotopic composition of stratospheric ozone, J. Geophys. Res., 111, D02302, doi:10.1029/2005JD006342, 2006.

Mauersberger, K.: Measurement of heavy ozone in the stratosphere, Geophys. Res. Lett., 8, 935-937, 1981.

Mauersberger, K., Morton, J., Schueler, B., and Stehr, J.: Multiisotope study of ozone: implications for the heavy ozone anomaly, Geophys. Res. Lett., 20, 1031-1034, 1993.

Mauersberger, K., Erbacher, B., Krankowsky, D., Günther, J., and Nickel, R.: Ozone Isotope Enrichment: Isotopomer-Specific Rate Coefficients, Science, 283, 370-372, 1999.

McLinden, C., Prather, M., and Johnson, M.: Global modeling of the isotopic analogues of $\mathrm{N}_{2} \mathrm{O}$ : Stratospheric distributions, budgets, and the ${ }^{17} \mathrm{O}-{ }^{18} \mathrm{O}$ mass-independent anomaly, J. Geophys Res., 108, 4233, doi:10.1029/2002JD002560, 2003.

Meier, A. and Notholt, J.: Determination of the isotopic abundances of heavy $\mathrm{O}_{3}$ as observed in arctic ground-based FTIR-spectra, Geophys. Res. Lett., 23, 551-554, 1996. 
Miller, C., Onorato, R., Liang, M., and Yung, Y.: Extraordinary isotopic fractionation in ozone photolysis, Geophys. Res. Lett., 32, L14814, doi:10.1029/2005GL023160, 2005.

Morton, J., Barnes, J., Schueler, B., and Mauersberger, K.: Laboratory Studies of Heavy Ozone, J. Geophys. Res., 95, 901-907, 1990.

Ndengué, S., Madronich, S., Gatti, F., Meyer, H., and Motapon, O.: Ozone photolysis: Strong isotopologue/isotopomer selectivity in the stratosphere, J. Geophys. Res., 119, 4286-4302, 2014.

Neely, R., English, J., Toon, O., Solomon, S., Mills, M., and Thayer, J.: Implications of extinction due to meteoritic smoke in the upper stratosphere, Geophys. Res. Lett., 38, L24808, doi:10.1029/2011GL049865, 2011.

Piccolo, C., Dudhia, A., and Payne, V. H.: Heavy ozone enrichments from MIPAS limb emission spectra, Atmos. Chem. Phys. Discuss., 9, 25127-25158, doi:10.5194/acpd-9-25127-2009, 2009.

Rinsland, C., Malathy Devi, V., Flaud, J., Camy-Peyret, C., Smith, M., and Stokes, G.: Identification of ${ }^{18} \mathrm{O}$-isotopic lines of ozone in infrared ground-based solar absorption spectra, J. Geophys. Res., 10719-10725, 1985.

Röckmann, T., Brenninkmeijer, C., Neeb, P., and Crutzen, P.: Ozonolysis of nonmethane hydrocarbons as a source of the observed mass independent oxygen isotope enrichment in tropospheric CO, J. Geophys. Res., 103, 1463-1470, 1998.

Rodgers, C.: Inverse Methods for Atmospheric Sounding: Theory and Practice, Series on atmospheric, oceanic and planetary physics: 1999, World Scientific, Singapore, 2000.

Sato, T. O., Sagawa, H., Yoshida, N., and Kasai, Y.: Vertical profile of $\delta^{18} \mathrm{OOO}$ from the middle stratosphere to lower mesosphere from SMILES spectra, Atmos. Meas. Tech., 7, 941-958, doi:10.5194/amt-7-941-2014, 2014.

Steck, T.: Methods for determining regularization for atmospheric retrieval problems, Appl. Optics, 41, 1788-1797, 2002.

Steck, T., von Clarmann, T., Fischer, H., Funke, B., Glatthor, N., Grabowski, U., Höpfner, M., Kellmann, S., Kiefer, M., Linden, A., Milz, M., Stiller, G. P., Wang, D. Y., Allaart, M., Blumenstock, Th., von der Gathen, P., Hansen, G., Hase, F., Hochschild, G., Kopp, G., Kyrö, E., Oelhaf, H., Raffalski, U., Redondas Marrero, A., Remsberg, E., Russell III, J., Stebel, K., Steinbrecht, W., Wetzel, G., Yela, M., and Zhang, G.: Bias determination and precision validation of ozone profiles from MIPAS-Envisat retrieved with the IMK-IAA processor, Atmos. Chem. Phys., 7, 3639-3662, doi:10.5194/acp-7-3639-2007, 2007.
Steinwagner, J., Milz, M., von Clarmann, T., Glatthor, N., Grabowski, U., Höpfner, M., Stiller, G. P., and Röckmann, T.: HDO measurements with MIPAS, Atmos. Chem. Phys., 7, 26012615, doi:10.5194/acp-7-2601-2007, 2007.

Stiller, G., von Clarmann, T., Funke, B., Glatthor, N., Hase, F., Höpfner, M., and Linden, A.: Sensitivity of trace gas abundances retrievals from infrared limb emission spectra to simplifying approximations in radiative transfer modelling, J. Quant. Spectrosc. Ra., 72, 249-280, 2002.

Thiemens, M. and Heidenreich, J.: The mass-independent fractionation of oxygen: a novel isotope effect and its possible cosmochemical implications, Science, 219, 1073-1075, 1983.

Tikhonov, A.: On the solution of incorrectly stated problems and a method of regularization, Dokl. Akad. Nauk SSSR+, 151, 501504, 1963.

von Clarmann, T. and Echle, G.: Selection of optimized microwindows for atmospheric spectroscopy, Appl. Optics, 37, 76617669, 1998.

von Clarmann, T., Glatthor, N., Grabowski, U., Höpfner, M., Kellmann, S., Kiefer, M., Linden, A., Tsidu, G., Milz, M., Steck, T., Wang, D., and Fischer, H.: Retrieval of temperature and tangent altitude pointing from limb emission spectra recorded from space by the Michelson Interferometer for Passive Atmospheric Sounding (MIPAS), J. Geophys. Res., 108, D003602, doi:10.1029/2003JD003602, 2003.

Worden, J., Kulawik, S., Frankenberg, C., Payne, V., Bowman, K., Cady-Peirara, K., Wecht, K., Lee, J.-E., and Noone, D.: Profiles of $\mathrm{CH}_{4}, \mathrm{HDO}, \mathrm{H}_{2} \mathrm{O}$, and $\mathrm{N}_{2} \mathrm{O}$ with improved lower tropospheric vertical resolution from Aura TES radiances, Atmos. Meas. Tech., 5, 397-411, doi:10.5194/amt-5-397-2012, 2012.

Yung, Y., DeMore, W., and Pinto, J.: Isotopic exchange between carbon dioxide and ozone via the $\mathrm{O}\left({ }^{1} \mathrm{D}\right)$ in the stratosphere, Geophys. Res. Lett., 18, 13-16, 1991. 